\title{
Red Colour Development and Loss in Pears
}

\author{
W.J. Steyn, S.J.E. Wand, D.M. Holcroft ${ }^{*}$ and G. Jacobs \\ Department of Horticultural Science, University of Stellenbosch, Private Bag X1, \\ Matieland, 7602 \\ South Africa \\ *Present address: Dole Fresh Vegetables, P.O. Box 1759, Salinas, CA 93902, USA.
}

Keywords: Anthocyanin, light, temperature, degradation, Pyrus communis.

\begin{abstract}
The endogenous and environmental regulation of red colour development in blushed and fully red pears is reviewed. Colour development in pears has an underlying developmental component. Generally, highest anthocyanin concentrations are attained in immature pears and colour tends to fade towards harvest. This is contrary to most other crop species where maximum pigmentation and colour are attained in ripe fruit and may relate to the photoprotective ability of anthocyanins. Because of this pigmentation pattern, net anthocyanin degradation at high temperatures results in pre-harvest red colour loss in susceptible pear cultivars. Susceptibility depends on the capacity to accumulate anthocyanin and on whether low temperatures are required for anthocyanin synthesis. Unlike apples, where red colour development in all cultivars seems to require or benefit from low temperatures, not all pear cultivars seem to respond to low temperatures. Light appears to have two opposing effects in pears, being required for anthocyanin synthesis, but also apparently increasing red colour loss through increased degradation of anthocyanin.
\end{abstract}

\section{INTRODUCTION}

Blushed pear fruit are sought after by consumers and fetch higher prices than green or fully red fruit (Huysamer, 1998). Red colour of blushed fruit is due to the presence of two anthocyanin pigments, cyanidin 3-galactoside and cyanidin 3-arabinoside, in hypodermal layers of the skin (Dussi et al., 1995). The presence and extent of the red blush, which varies considerably between seasons and between cultivars, determines the profitability of blushed cultivars. Differences in the redness of pear peel primarily relate to differences in pigment levels (Steyn et al., 2004a). Hence, poor red colour and the downgrading of blushed pears can be attributed to low anthocyanin levels at harvest. In order to attain regular yields of sufficiently blushed fruit, producers need to be aware of the factors that influence pear red colour development.

In contrast with numerous reviews on red colour development in apples, very little is known about the regulation of pear colour development. However, recent evidence indicates that the developmental regulation of red colour in pears differs considerably from that in other fruit kinds. While in most fruit kinds anthocyanin synthesis peaks during ripening (Macheix et al., 1990; Saure, 1990), pear red colour apparently fades towards harvest (Steyn et al., 2004a). This difference in developmental regulation influences the effect of environmental factors on red colour development. In apples, poor red colour at harvest can be attributed to insufficient anthocyanin accumulation during the ripening-associated peak in synthesis (Saure, 1990). Poor synthesis normally relates to low light levels within the tree canopy and/or high temperatures (Saure, 1990). In pears, high day temperatures and light may contribute to the fading of red colour by increasing anthocyanin degradation (Steyn et al., 2004b).

In this review we discuss the endogenous and environmental regulation of red colour development in blushed and fully red pears as well as the contribution of anthocyanin degradation to pear colour at harvest. We also refer to the extensive literature available on the regulation of colour development in apples, the fruit kind of choice for 
studies on fruit colour development. We briefly speculate on the possible functionality of the pear pigmentation pattern.

\section{DEVELOPMENTAL REGULATION OF PEAR COLOUR}

\section{Pear Pigmentation Pattern}

The ability to accumulate anthocyanin is a function of the developmental stage of fruit (Saure, 1990). In many fruit kinds, changes in colour and accumulation of anthocyanins coincide with ripening (Macheix et al., 1990). In contrast, fully red and blushed pears generally attain their highest anthocyanin concentrations about midway between anthesis and harvest (Dussi et al., 1997; Steyn et al., 2004a; Fig. 1). Thereafter, anthocyanin concentrations gradually decrease and red colour fades towards harvest due to a combination of decreasing synthesis, natural turnover, degradation at high temperatures and dilution (Steyn et al., 2004b).

The maximum anthocyanin concentration reached and the severity of colour fading has a considerable influence on fruit colour at harvest (Steyn et al., 2004b). These two factors are interrelated: the rapidity and extent to which red colour fades also depend on the capacity to accumulate anthocyanin. An exponential relationship exists between anthocyanin concentration and hue angle $\left(0^{\circ}=\right.$ red-purple, $90^{\circ}=$ yellow, $180^{\circ}=$ bluishgreen and $270^{\circ}=$ blue) at high pigment levels and a linear relationship at lower pigment levels (Steyn et al., 2004b). Hence, much larger reductions in anthocyanin concentration are required to induce a similar extent of visible colour change in well-coloured fruit with high anthocyanin concentrations compared to poorly coloured fruit containing little anthocyanin (Fig. 2). This means that despite considerable reductions in anthocyanin concentration, fruit containing high anthocyanin concentrations changes little in redness while fruit containing little anthocyanin rapidly loses redness and becomes green under conditions favouring degradation (Steyn et al., 2004b). Consequently, fruit of blushed cultivars with a relatively low capacity for anthocyanin accumulation is much more prone to significant red colour loss prior to harvest. These cultivars also experience greater fluctuation in redness between seasons due to the poor buffering of red colour by the low anthocyanin concentrations (Steyn et al., 2004b).

\section{Molecular and Biochemical Basis of the Pear Pigmentation Pattern}

The induction of genes of the anthocyanin biosynthetic pathway (see review by Saito and Yamazaki, 2002) is coordinated and controlled by the action of regulatory genes activated by developmental and environmental stimuli (Holton and Cornish, 1995). We are not aware of any studies on the expression of anthocyanin regulatory genes in fruit.

Apple peel and grape berries have been used to study the correlation between expression and activity of enzymes of the anthocyanin biosynthesis pathway and colour development (Ju et al., 1999; Kondo et al., 2002; Ban et al., 2003). In both these fruit kinds, red colour development appears to be regulated by the expression and activity of UDPGalactose: flavonoid-3-o -glycosyltransferase (UFGT), the last enzyme of the anthocyanin biosynthetic pathway. Enzymes prior to UFGT were expressed and active at stages of fruit development when red colour was absent. Products of reactions catalysed by these "earlier" enzymes can be diverted into numerous other phenolic pathways with diverse functions in, e.g., protection against herbivory, ultraviolet radiation and pathogen attack (McClure, 1975). UFGT activity in 'Rosemarie' and 'Bon Rouge' pear peel was found to increase over fruit development (Steyn et al., 2004a). Hence, it seems unlikely that UFGT activity is the factor that limits anthocyanin synthesis towards harvest in pear peel.

\section{Functionality of the Pear Pigmentation Pattern}

Anthocyanin accumulation and colour changes at harvest may aid seed dispersal (Harborne, 1965). Since red colour peaks in immature fruit, it is unlikely that pear 
anthocyanins play a similar role. Recently, resistance to light stress of peel of different pear cultivars were found to increase with increasing redness of the peel (Steyn, 2003). This suggests a link between the presence of anthocyanin in pear peel and the ability of anthocyanins to protect photosynthesising tissues from light stress. Light interception by anthocyanins reduces the light levels incident on the underlying chloroplasts and so provides protection from excess light.

However, it has been reported in some pear cultivars that red colour increases towards harvest (Dussi et al., 1997), thus arguing against a general function for pear anthocyanins in photoprotection. Also, red and blushed cultivars are selected for aesthetic reasons, often from green parents, so that increased anthocyanin levels do not necessarily confer any adaptive advantage (Harborne, 1965). Protection provided by anthocyanins can simply be fortuitous. By nature, anthocyanins should protect underlying photosynthesising tissues from light stress whenever present, but this may not necessarily be the reason for their presence. Acceptance of a photoprotective function for anthocyanin in pear peel would depend on whether developmental changes in the ability to accumulate anthocyanin reflect similar changes in susceptibility to light stress.

\section{ENVIRONMENTAL REGULATION OF COLOUR}

\section{Light}

Light has two opposing effects on pear red colour, being required for anthocyanin synthesis, but also contributing to red colour loss through anthocyanin degradation (Steyn et al., 2004b). In most fruit, plant organs and tissues, light is a prerequisite for anthocyanin synthesis (Mancinelli, 1983). Pears are no exception. This can be inferred from the ability to prevent red colour development by enclosing fruit in lightimpermeable bags (Steyn et al., 2004b). Anthocyanin concentrations also rapidly decrease in the absence of light, indicating that continued light-requiring synthesis is necessary to make up for dilution and turnover of anthocyanin (Steyn et al., 2004b). The rate of anthocyanin synthesis in apples increases linearly with increasing light energy (Proctor, 1974). Hence, anthocyanin concentrations generally relate to light levels experienced on sun-exposed and shaded surfaces of individual fruit, as well as to differences within the cluster, bearing position, and position within the tree canopy (Awad et al., 2000). However, light is also an important contributor to anthocyanin degradation and discoloration of food products (Francis, 1989), and was found to increase anthocyanin degradation in detached apple and pear peel, either directly or via radiant heating (Marais et al., 2001a; Steyn et al., 2004b).

Light stimulation of anthocyanin synthesis and degradation may occur simultaneously. Whether light exposure results in a colour gain or colour loss depends on whether environmental and endogenous conditions are favourable for anthocyanin synthesis. When unfavourable temperatures, or other factors, limit anthocyanin synthesis, light may contribute more to degradation than to synthesis, giving rise to colour loss. While it is imperative that apple fruit are exposed to high light intensities during the ripening-associated peak in anthocyanin synthesis to attain good colour, shading of 'Sensation Red Bartlett' pears in the month before harvest reduced the decrease of anthocyanin levels and the fading of red colour (Dussi et al., 1995). As the ability of apple peel to synthesise anthocyanin increases towards maturity, the extent of light-induced anthocyanin degradation should become relatively small compared to the extent of synthesis. In contrast, since anthocyanin synthesis in pear peel tends to decrease towards harvest (Steyn et al., 2004b), the contribution of light to degradation can be expected to predominate. The contribution of light-induced anthocyanin degradation to fruit colour at harvest should increase as the ability of fruit of different pear cultivars to accumulate anthocyanin decreases.

\section{Temperature}

1. Synthesis. Low temperatures increase and high temperatures decrease anthocyanin accumulation in many fruit kinds and plant tissues (Steyn et al., 2002). To date, colour 
development in all apple cultivars studied thus far have benefited from low temperatures (Curry, 1997; Reay, 1999; Steyn et al., 2004b). Studies on detached apples indicated that anthocyanin synthesis benefits from induction at low temperatures $\left(\leq 15^{\circ} \mathrm{C}\right)$ whether in light or darkness, while subsequent accumulation of anthocyanin requires irradiation at higher temperatures $\left(20-25^{\circ} \mathrm{C}\right)$ (Curry, 1997; Reay, 1999). Little anthocyanin is produced at lower $\left(15^{\circ} \mathrm{C}\right)$ or higher $\left(35^{\circ} \mathrm{C}\right)$ temperatures (Curry, 1997). A similar diurnal temperature requirement for maximal anthocyanin accumulation was found in maize (Christie et al., 1994), suggesting a more general response. Apparently, low temperatures induce expression of anthocyanin regulatory and biosynthetic pathway genes, but milder temperatures and light are required for the synthesis of anthocyanin (Christie et al., 1994). Previously Tan (1980) and Faragher (1983) found much higher phenylalanine ammonialyase (PAL) activity in apples held at low $\left(6-10^{\circ} \mathrm{C}\right)$ compared to high temperatures $\left(20^{\circ} \mathrm{C}\right)$.

Unlike apples, amongst four pear cultivars studied only 'Rosemarie' increased in red colour in response to low temperatures (Steyn et al., 2004a; Fig. 3). Assessment of PAL and UFGT activities in 'Rosemarie' and 'Bon Rouge' in response to cold fronts confirmed the differential induction of anthocyanin synthesis by low temperatures. Red colour as well as PAL and UFGT activities increased in 'Rosemarie' peel in response to the passing of a cold front early during fruit development (Steyn et al., 2004a). PAL and UFGT activity correlated most strongly with daily minimum temperatures, suggesting their induction at low temperatures. This is in agreement with Christie et al. (1994). Enzyme activity did not respond to low temperatures in the red cultivar 'Bon Rouge' or in either cultivar when a cold front passed in the week before harvest. This lack of response to low temperatures at the late stage of fruit development is consistent with the decreasing ability of pears to synthesise anthocyanin towards harvest (Steyn et al., 2004b).

Failure to induce colour development in detached pears has prevented the determination of the optimum temperature range for anthocyanin synthesis (Marais et al., 2001b; Steyn et al., 2004a). However, the strong negative correlation found between redness of 'Rosemarie' fruit and average daily temperatures (Steyn et al., 2004a) seems to indicate that both night and day temperatures are important.

2. Degradation. Together with light, high temperature is the major factor involved in red colour loss in fruit, flowers and vegetative tissues (Biran and Halevy, 1974; Oren-Shamir and Levi-Nissim, 1997; Steyn et al., 2004b). Anthocyanin degradation and colour loss was found to increase linearly between 10 and $30^{\circ} \mathrm{C}$ in detached apples and pears (Steyn et al., 2004b). Red colour loss and anthocyanin degradation in attached 'Rosemarie' pears also corresponded with periods of high temperature. The hue of fruit was found to increase by up to $5^{\circ}$ during a single hot day (Fig. 3). Alternating cycles of high and low temperatures gave rise to fluctuation of 'Rosemarie' colour between red and green (Steyn et al., 2004b; Fig. 3). Other pear cultivars showed less fluctuation in red colour due to their higher anthocyanin levels.

The mechanism of light and temperature-induced degradation or natural turnover of anthocyanin in fruit is not known. Red colour loss in food products is generally attributed to three enzyme groups potentially able to degrade anthocyanins; 1glycosidases, peroxidases and polyphenoloxidases (Macheix et al., 1990). However, high temperatures and light can degrade anthocyanin without enzymatic mediation (Attoe and Von Elbe, 1981).

\section{CONCLUSION}

In most fruit kinds including apple, the extent of red colour at harvest is determined by anthocyanin accumulation during a ripening-associated peak in synthesis. Pears display an atypical anthocyanin accumulation pattern, which involves the attainment of maximum anthocyanin concentrations about midway between anthesis and harvest and a slow decrease in synthesis and colour thereafter. Due to this pigmentation pattern, degradation of anthocyanin in response to light and high temperatures plays an important role in the determination of pear red colour at harvest. Furthermore, colour 
development in pears is light dependent, but in contrast to apples, only one cultivar required low temperatures for anthocyanin synthesis. Evidently, the molecular and biochemical basis of the developmental and environmental regulation of pear colour requires further study. It should prove a fruitful future field of research.

\section{Literature Cited}

Attoe, E.L. and Von Elbe, J.H. 1981. Photochemical degradation of betanine and selected anthocyanins. J. Food Sci. 46:1934-1937.

Awad, M.A., De Jager, A. and Van Westing, L.M. 2000. Flavonoid and chlorogenic acid levels in apple fruit: characterisation of variation. Sci. Hort. 83:249-263.

Ban, T., Ishimaru, M., Kobayashi, S., Shiozaki, S., Goto-Yamamoto, N. and Horiuchi, S. 2003. Abscisic acid and 2,4-dichlorophenoxyacetic acid affect the expression of anthocyanin biosynthetic pathway genes in 'Kyoho' grape berries. J. Hort. Sci. Biotech. 78:586-589.

Biran, I. and Halevy, A.H. 1974. Effects of short-term heat and shade treatments on petal colour of 'Baccara' Roses. Physiol. Plant. 31:180-185.

Christie, P.J., Alfenito, M.R. and Walbot, V. 1994. Impact of low-temperature stress on general phenylpropanoid and anthocyanin pathways: Enhancement of transcript abundance and anthocyanin pigmentation in maize seedlings. Planta 194:541-549.

Curry, E.A. 1997. Temperatures for optimal anthocyanin accumulation in apple tissue. J. Hort. Sci. 72:723-729.

Dussi, M.C., Sugar, D., Azarenko, A.N. and Righetti, T.L. 1997. Colometric characterization of red pear cultivars. Fruit Var. J. 51:39-43.

Dussi, M.C., Sugar, D. and Wrolstad, R.E. 1995. Characterizing and quantifying anthocyanins in red pears and the effect of light quality on fruit color. J. Amer. Soc. Hort. Sci. 120:785-789.

Faragher, J.D. 1983. Temperature regulation of anthocyanin accumulation in apple skin. J. Exp. Bot. 34:1291-1298.

Francis, F.J. 1970. Anthocyanins in pears. HortScience 5:42.

Harborne, J.B. 1965. Flavonoids: Distribution and contribution to plant colour, p247-278. In: T.W. Goodwin (ed.). Chemistry and biochemistry of plant pigments. Academic Press, London, UK.

Holton, T.A. and Cornish, E.C. 1995. Genetics and biochemistry of anthocyanin biosynthesis. Plant Cell 7:1071-1083.

Huysamer, M. 1998. Report of the blushed pear workgroup: Perceptions, facts and questions. Proc. Cape Pomological Association Tech. Symp., Cape Town, South Africa, 2-3 June 1998, 187-192.

Kondo, S., Hiraoka, K., Kobayashi, S., Honda, C. and Terahara, N. 2002. Changes in the expression of anthocyanin biosynthetic genes during apple development. J. Amer. Soc. Hort. Sci. 127:971-976.

Ju, Z., Liu, C., Yuan, Y., Wang, Y. and Liu, G. 1999. Coloration potential, anthocyanin accumulation, and enzyme activity in fruit of commercial apple cultivars and their F1 progeny. Sci. Hort. 79:39-50.

Macheix, J.J., Fleuriet, A. and Billot, J. 1990. Fruit phenolics. CRC Press, Boca Raton, FL.

Mancinelli, A.L. 1983. The photoregulation of anthocyanin synthesis, p640-661. In: W. Shropshire Jr. and H. Mohr H (eds.). Photomorphogenesis. Springer-Verlag, Berlin, Germany.

Marais, E., Jacobs, G. and Holcroft, D.M. 2001a. Colour response of 'Cripps' Pink' apples to postharvest irradiation is influenced by maturity and temperature. Sci. Hort. 90:31-41.

Marais, E., Jacobs, G. and Holcroft, D.M. 2001b. Postharvest irradiation enhances anthocyanin synthesis in apples but not in pears. HortScience 36:738-740. 
McClure, J.W. 1975. Physiology and functions of flavonoids, 970-1055. In: Harbome, J.B., T.J. Mab1y and H. Mably (eds.). The flavonoids. Chapman \& Hall Ltd, London, UK.

Oren-Shamir, M. and Levi-Nissim, A. 1997. Temperature effects on the leaf pigmentation of Continus coggygria 'Royal Purple'. J. H01i. Sci. 72:425-432.

Proctor, J.T.A. 1974. Color stimulation in attached apples with supplementruy light. Can. J. Plant Sci. 54:499-503.

Reay, P.F. 1999. The role of low temperatures in the development of the red blush on apple fruit ('Granny Smith'). Sci. Hort. 79:113-119.

Saito, K. and Yamazaki, M. 2002. Biochemistry and moleculru biology of the late-stage of biosynthesis of anthocyanin: lessons fr-om Perilla frutescens as a model plant. New Phytol. 155:9-23.

Saure, M.C. 1990. Extemal control of anthocyanin fonnation in apple. Sci. H01i. 42:181218.

Steyn, W.J. 2003. Red colour development and loss in peru fruit. PhD-thesis, University of Stellenbosch, South Afr.ica.

Steyn, W.J., Wand, S.J.E., Holcroft, D.M. and Jacobs, G. 2002. Anthocyanins in vegetative tissues: A proposed unified function in photoprotection. New Phytol. $155: 349-361$.

Steyn, W.J., Holcroft, D.M., Wand, S.J.E. and Jacobs, G. 2004a. Regulation of pear color development in realtion to activity of flavonoid enzymes. J. Amer. Soc. H01i. Sci. 129:1-6.

Steyn, W.J., Holcroft, D.M., Wand, S.J.E. and Jacobs, G. 2004b. Anthocyanin degradation in detached pome fruit with reference to prehruvest red color loss and pigmentation pattems of blushed and fully red peru.s. J. Amer. Soc. H0li. Sci. 129:712.

Tan, S.T. 1980. Phenylalanine ammonia-lyase and the phenylalanine ammonia-lyase inactivating system: Effects of light, temperature and mineral deficiencies. Aust. J. Plant Physiol. 7:159-167.

Figures

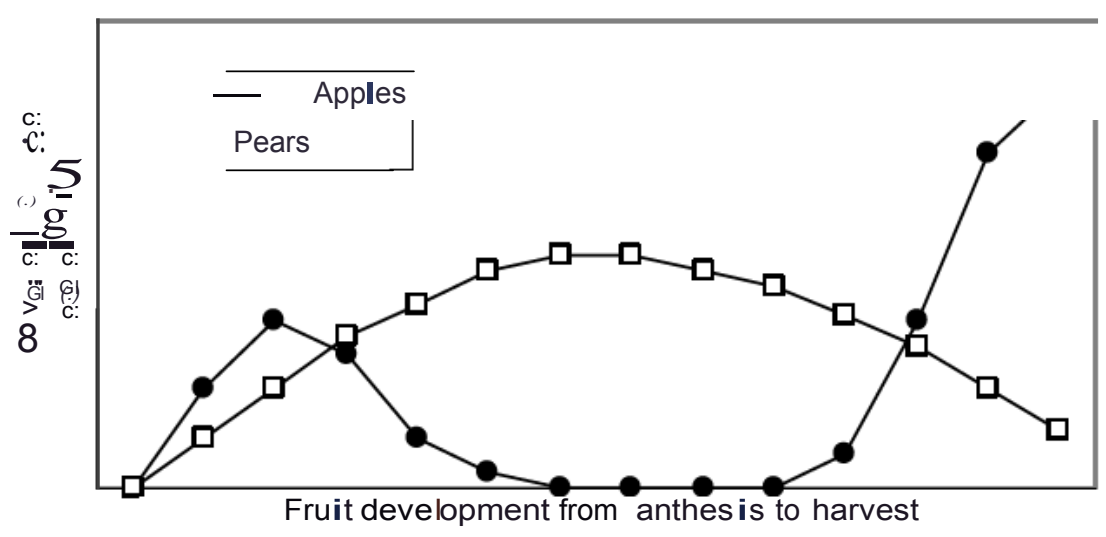

Fig. 1. General anthocyanin accumulation pattems in apples and perus. 


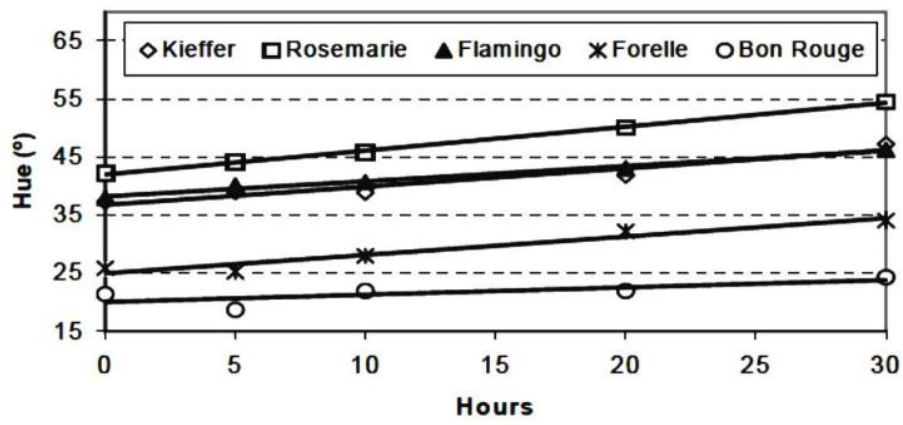

\begin{tabular}{lcc}
\hline Cultivar & Gradient $\left({ }^{\circ} \mathrm{h}^{-1}\right)$ & Y-Intercept \\
\hline 'Bon Rouge' & $0.13 \mathrm{~b}$ & $20.0 \mathrm{~d}$ \\
'Forelle' & $0.31 \mathrm{a}$ & $25.9 \mathrm{c}$ \\
'Flamingo' & $0.26 \mathrm{ab}$ & $38.2 \mathrm{ab}$ \\
'Kieffer' & $0.34 \mathrm{a}$ & $36.2 \mathrm{~b}$ \\
'Rosemarie' & $0.41 \mathrm{a}$ & $42.0 \mathrm{a}$ \\
\hline LSD & 0.134 & 4.68 \\
Pr $>$ F & 0.0245 & 0.0001 \\
\hline
\end{tabular}

Fig. 2. Changes in the hue of different red and blushed pear cultivars subjected for 30 hours to strong HPS light $\left(1200 \mu \mathrm{mol} \mathrm{m} \mathrm{m}^{-2}\right)$ at $40^{\circ} \mathrm{C}$. Increasing hue angles denote a reduction in redness. Adapted from Steyn (2003).
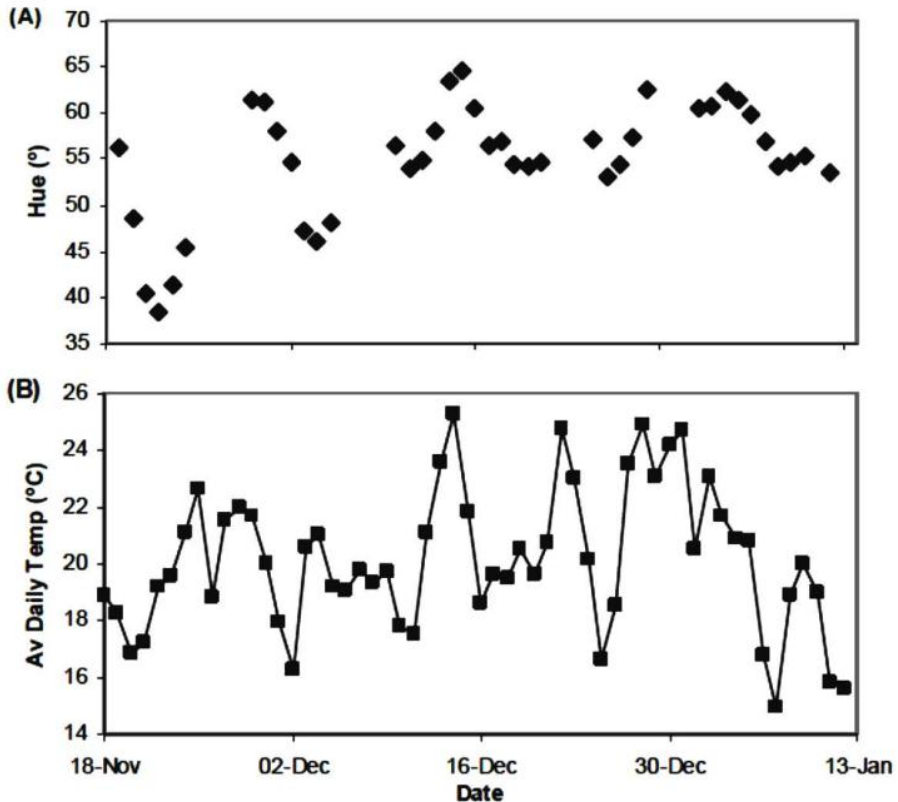

Fig. 3. (A) Daily changes in hue angle of 'Rosemarie' pears during the 2001/2002 season. Hue angles, measured at the reddest position on fruit, fluctuate between $0^{\circ}$ (redpurple) and $90^{\circ}$ (yellow). Average daily temperatures are presented in (B). (Adapted from Steyn et al., 2004a). 